\title{
Transitional care in skilled nursing facilities: a multiple case study
}

\author{
Mark Toles ${ }^{*}$, Cathleen Colón-Emeric ${ }^{2}$, Mary D. Naylor ${ }^{3}$, Julie Barroso ${ }^{4}$ and Ruth A. Anderson ${ }^{5}$
}

\begin{abstract}
Background: Among hospitalized older adults who transfer to skilled nursing facilities (SNF) for short stays and subsequently transfer to home, twenty two percent require additional emergency department or hospital care within 30 days. Transitional care services, that provide continuity and coordination of care as older adults transition between settings of care, decrease complications during transitions in care, however, they have not been examined in SNFs. Thus, this study described how existing staff in SNFs delivered transitional care to identify opportunities for improvement.

Methods: In this prospective, multiple case study, a case was defined as an individual SNF. Using a sampling plan to assure maximum variation among SNFs, three SNFs were purposefully selected and 54 staff, patients and family caregivers participated in data collection activities, which included observations of care $(N=235)$, interviews $(N=66)$ and review of documents $(N=35)$. Thematic analysis was used to describe similarities and differences in transitional care provided in the SNFs as well as organizational structures and the quality of care-team interactions that supported staff who delivered transitional care services.

Results: Staff in Case 1 completed most key transitional care services. Staff in Cases 2 and 3, however, had incomplete and/or absent services. Staff in Case 1, but not in Cases 2 and 3, reported a clear understanding of the need for transitional care, used formal transitional care team meetings and tracking tools to plan care, and engaged in robust team interactions.
\end{abstract}

Conclusions: Organizational structures in SNFs that support staff and interactions among patients, families and staff appeared to promote the ability of staff in SNFs to deliver evidence-based transitional care services. Findings suggest practical approaches to develop new care routines, tools, and staff training materials to enhance the ability of existing SNF staff to effectively deliver transitional care.

Keywords: Older adults, Transitional care, Skilled nursing facilities

\section{Background}

Following hospitalization for acute conditions, it is increasingly common for older adults in the U.S. to transition to a skilled nursing facility (SNF) for medical, nursing and rehabilitative care, after which they will transition again to home [1, 2]. In 2013, 1.7 million older adults, who discharged from U.S. hospitals, transferred to SNFs, where the average length of stay was 24 days and the total cost to Medicare was $\$ 28.8$ billion [3]. In this study of transitional care in SNFs, it is important to note that the term "SNF" refers to nursing homes in

\footnotetext{
* Correspondence: mtoles@email.unc.edu

'University of North Carolina at Chapel Hill, School of Nursing, 7460

Carrington Hall, Chapel Hill, NC 27599, USA

Full list of author information is available at the end of the article
}

which staff provide care before patient transitions to home or other settings.

Transitional SNF patients experience risk for poor health outcomes as they transfer between settings and providers of care $[2,4]$. The advanced age, dependence on others for daily support and lower socioeconomic status of many SNF patients contribute to their vulnerability to poor health outcomes; for example, in 2013, $73 \%$ of SNF patients were aged 75 years or older, $49 \%$ had limitations in 3 to 6 activities of daily living (such as dressing, bathing, and eating), and $37 \%$ were dually eligible for Medicare and Medicaid [5]. After transitions from SNFs to home, patients and their primary caregivers often struggle to self-manage health care tasks, 
such as monitoring and responding to changes in health, taking or administering the correct medications, and participating in follow-up rehabilitative and medical treatments [4]. Available data indicate that SNF patients experience poor health outcomes after transitioning from SNFs to home: $22 \%$ required emergency services and/or hospital stays within 30 days of SNF discharge, and $39 \%$ required emergency services and/or hospital stays within 90 days $[6,7]$. This finding suggests that SNF patients and their primary caregivers (e.g. family members or friends who assist the patient) may not be prepared for care transitions from SNFs to home. It also suggests that SNF patients would benefit from transitional care services, designed to "promote coordination and continuity of care" as they transition between settings and providers of care $[8,9]$.

Randomized trials of formal transitional care interventions in hospitals and in one SNF have demonstrated reductions in the rate of hospital readmissions after older adults transfer to home [10-13]. These effective interventions used specialized transitional care staff to provide services before discharge (e.g., medication reconciliation and disease self-management education), services that bridged hospital and communitybased care (e.g., patient-centered discharge records) and services after discharge services at home (e.g., follow-up calls or home visits) [11]. However, little is known about who delivers transitional care in SNFs, what transitional care services are provided, or how the organizational structure supports the staff members that deliver transitional care services [14, 15]. Moreover, resource limitations in SNFs likely prohibit adding transitional care staff, used in many hospitalbased transitional care interventions, and data are needed to describe how existing staff members can be trained and supported to provide needed care.

Our purpose was to describe how organizational structures and staff interactions are used by existing SNF staff to deliver transitional care services. The aims of this prospective, multiple case study were to: 1) describe organizational structures in SNFs that facilitated transitional care services; 2) describe careteam interaction strategies (such as sharing information and providing feedback to solve problems) that promoted timely and complete transitional care; and 3) compare similarities and differences in transitional care services that existing staff provided for SNF patients and their primary caregivers in three SNFs. The rationale for the study was to identify targets for intervention and/or quality improvement programs to improve transitional care delivery by existing staff in SNFs, and thereby improve SNF patient outcomes after transfers to home.

\section{Guiding models}

We drew on two existing models to guide the concepts to be described in this study. First, we used Donabedian's Model of Health Care Quality to guide our description of (a) organizational structures (e.g., staff knowledge, tools and routines) and (b) care processes (e.g., transitional care services) [16]. See Table 1. Using the logic of Donabedian's Model of Health Care Quality, we anticipated that organizational structures in SNFs would increase the ability of staff to deliver transitional care services [16].

Organizational structures were defined as the supports in SNFs that are available for transitional care services $[17,18]$. As described in Table 1, three organizational structures were considered, including (a) staff knowledge of transitional care and staff understanding of the importance of providing transitional care, (b) care routines (such as scheduled meetings to plan transitional care services) and (c) tools (such as templates in the electronic medical record for documenting care). In the three SNFs studied, we examined how qualitative differences in staff knowledge, care routines and tools were related to the way staff delivered transitional care services.

While the organizational structures provide supports for providing transitional care, it is the quality of the interactions among members of patient care-teams that facilitate individualized care to be planned and implemented $[19,20]$. For example, in a prior study, we found that transitional care was embedded in the informal interactions between providers and patients, and that staff more effectively delivered transitional care services when they worked in designated teams, rather than alone or in dyads [21]. Thus, we drew on Anderson et al.'s Model of Local Interaction [19], to guide our descriptions of staff interactions (see Table 1). Based on the Model of Local Interaction, we anticipated that care-team interactions promoting strong connections among team members, new information exchange, and team problem-solving would also promote the ability of staff to effectively deliver transitional care services. Thus we defined careteam interactions as behaviors (Table 1) that care-team members used to (a) connect with others (such as pitching in to help others), (b) exchange information (such as explaining the meaning of information), and (c) solve problems in care (such as including diverse team members in decision making activities) [19]. In the three SNFs studied, we examined how qualitative differences in care-team interactions were associated with the ability of staff to deliver transitional care services.

Together, high quality organizational structures and care-team interactions will allow staff to deliver transitional care services, which are the specific services to promote continuity and coordination of care as older 
Table 1 Conceptual model: transitional care in SNFs Organizational Structure: Three organizational supports in SNFs that facilitate delivery of transitional care services [18].

$\begin{array}{ll}\text { Structure } & \text { Definition } \\ \text { Staff knowledge } & \text { Professional staff members (e.g., physicians, } \\ & \text { nurses, rehabilitation therapists and social } \\ & \text { workers) are (a) available to patients and } \\ & \text { family caregivers and (b) skilled in delivering } \\ & \text { transitional care. } \\ & \text { Predictable schedules that staff members } \\ \text { Care routines } & \text { team meetings focused on patient and } \\ & \text { caregiver needs, family and patients } \\ & \text { meetings, and cycles of care delivery and } \\ & \text { assessment to monitor outcomes. } \\ & \text { Templates and information technology that } \\ & \text { staff use to document transitional care } \\ & \text { services and for create individualized patient } \\ & \text { and caregiver written instructions. }\end{array}$

Care-team Interactions: Informal interactions among patients, caregivers and staff that help them form relationships (connect), exchange information, and solve problems $[20,33]$.

Interaction Definition

Connect Staff members are (a) approachable for building relationships with patients and family caregivers; (b) pitch-in to help each other, patients and family caregivers; (c) recognize each other as care team members.

Exchange information Staff members (a) listen to each other, patients, and family caregivers; (b) relay and verify the accuracy of new information; (c) communicate in pairs and larger groups of care-team members.

Solve problems Staff members ask questions and give feedback to develop new information or understanding. Groups of care-team members participate in conversations to solve emerging problems in care.

Transitional Care Services: Eight evidence-based care processes that promote continuity and coordination of care as older adults transition between settings and providers of care [11-13].

Process Definition

Assess

Evaluates patient and caregiver preferences, strengths and needs related to health care for ensuring patients' self-care ability and safety at home.

Plan

Creates multidisciplinary goals and measures to deliver transitional care based on assessments of patient and caregiver preferences, strengths and needs.

Engage Collaborates with patients and caregivers to ensure that (a) implemented plans are congruent with their preferences and goals and (b) patients feel motivated to implement transition plans.

Reconcile medication Verifies a correct medication list, using medications lists from home, hospital and SNF stays, and orders for planned care at home. Inaccuracies and errors of omission or commission are corrected.
Table 1 Conceptual model: transitional care in SNFs (Continued)

\begin{tabular}{|c|c|}
\hline Refer & $\begin{array}{l}\text { Schedules and confirms the feasibility of } \\
\text { services planned for care at home, e.g., MD } \\
\text { appointments, home care, social services, } \\
\text { rehabilitation, and tests/procedures. }\end{array}$ \\
\hline Educate & $\begin{array}{l}\text { Ensures that patients and caregivers have a } \\
\text { written record and clear understanding of } \\
\text { (a) the transition plan; (b) the name, purpose, } \\
\text { dosage, administration, and side effects of } \\
\text { medications, and (c) how to recognize and } \\
\text { respond to warning signs changes in health } \\
\text { or medical conditions. }\end{array}$ \\
\hline Transfer & $\begin{array}{l}\text { Sends timely and accurate summaries of } \\
\text { SNF care and plans for the transition home } \\
\text { to community providers of care. }\end{array}$ \\
\hline Follow-up & $\begin{array}{l}\text { Provides follow-up phone calls or home } \\
\text { visits to promote patients' and family } \\
\text { caregivers' implementation of transition } \\
\text { plans at home. }\end{array}$ \\
\hline
\end{tabular}

adults transition between settings and providers of care $[11,13]$. As described in Table 1, we defined eight transitional care services that have been associated with improved patient outcomes after transitions from hospitals to home $[11,13]$. In the three SNFs studied, we examined whether these eight transitional care services were used to prepare individual patients for transitions from the SNF to home.

\section{Methods}

We used a prospective, multiple case study design to describe the delivery of transitional care services in a purposefully selected sample of three SNFs [22, 23]. In this study, we (a) collected and analyzed data from observations, interviews and document reviews from multiple study participants at multiple points in time and (b) described qualitative differences in organizational structures, care-team interactions and transitional care services in the sample of cases. We defined a "case" as a SNF; within each SNF, data collection was focused on one patient, their primary family/friend caregiver(s) and the team of SNF staff who provided transitional care services. Baseline data about the organization of care in the SNF (e.g., staff roles, care routines and tools) were collected from staff; then, prospective, comprehensive case data about the care for an individual patient in each study SNF were collected from the patient's admission to the SNF until discharge to home. All of the authors participated in the analysis and interpretation of data.

\section{Ethics and consent}

The protocols in this study were approved by the Institutional Review Board at Duke University and underwent annual review (Pro00014871). Written permission to conduct the study was obtained from the administrator in each participating SNF. An informed consent 
procedure was used with all study participants, including use of a plain language statement of study procedures and risks. All individuals who provided study data signed an informed consent.

\section{Setting and participant sample}

As described in Table 2, a sample of three SNFs was purposefully selected, based on variations in facility size, profit status, star-ratings in Nursing Home Compare (a federally administered database describing the quality of care in U.S. nursing homes) [24], and the percentage of Medicaid eligible patients in the facility. These three SNFs were selected, as a form of maximum variation sampling [25], because we believed their differences would allow us to address the study aims and generate meaningful hypotheses to guide further research.

In each SNF, one patient was recruited. The inclusion criterion for patients was the ability to speak in English (as indicated by the medical record and conversations during recruitment activities). Patents were excluded if they had more than mild cognitive impairment (as indicated by the description of the patient's mental status in the hospital and SNF medical records, a verbal report provided by the director of nursing indicating the patient's understanding of treatments and plans, and the patient's ability to fully participate in study recruitment and consenting procedures). The first patient admitted to the SNF who met the inclusion criterion was recruited by the lead author. No patients declined to participate. A total of three patients, one from each SNF, participated in the study (see Table 2). Primary caregivers (e.g., family members or friends) were recruited if they spoke English, as indicated during recruitment conversations. Two primary caregivers participated in the study and none declined to participate (see Table 2). Staff members were recruited if they were willing to participate in the study; these included (a) department managers (such as director or assistant director of nursing, department heads of rehabilitation or social services, or medical directors) or staff who directly provided elements of transitional care with the recruited SNF patient (such as nurses, social workers and rehabilitation therapists). A total of 49 staff participated: 15 in SNF 1, 17 in SNF 2, and 17 in SNF 3 (see Table 2). Two staff members declined to participate in the study.

\section{Data collection}

Using procedures and instruments from prior research [21], data were collected over approximately 10 weeks in each SNF in three phases (see Table 3 for an illustration of the data collection schedule in SNFs). In weeks 1-3, data were collected by observing scheduled meetings, reviewing policy and procedure documents, interviewing department heads and selected clinical staff for the purpose of describing the plan or supports for providing transitional care in each SNF (see Table 3). In weeks 4-8, the SNF patient, primary caregiver and direct care staff were recruited and data were collected (e.g., interviews, observations and document or chart reviews) to describe how staff delivered transitional care over time with an

Table 2 Description of SNFs and study participants ${ }^{a}$

\begin{tabular}{|c|c|c|c|}
\hline Case & 1 & 2 & 3 \\
\hline \multicolumn{4}{|l|}{ SNF Characteristics } \\
\hline Ownership & Private & Chain & Chain \\
\hline Profit status & For profit & For profit & For profit \\
\hline Size (bed count) & $100-150$ & $<100$ & $>150$ \\
\hline$\%$ Medicaid & $<20 \%$ & $>50 \%$ & $>50 \%$ \\
\hline Nursing Home Compare & 5 stars & 4 stars & 1 star \\
\hline \multicolumn{4}{|l|}{ Patients Characteristics } \\
\hline Patient age/gender & 75 yrs./female & 78 yrs./female & $69 \mathrm{yrs} . / \mathrm{female}$ \\
\hline Patient length of stay & 28 days & 20 days & 20 days \\
\hline Patient medical condition & $\begin{array}{l}\text { Cervical fusion and multiple } \\
\text { health conditions }\end{array}$ & $\begin{array}{l}\text { Kidney failure and multiple } \\
\text { health conditions }\end{array}$ & $\begin{array}{l}\text { Lumbar fusion and multiple } \\
\text { health conditions }\end{array}$ \\
\hline \multicolumn{4}{|l|}{ Primary Caregiver Characteristics } \\
\hline Enrolled & None Available & Yes & Yes \\
\hline Relationship to patient & $\mathrm{n} / \mathrm{a}$ & Daughter & Daughter \\
\hline \multicolumn{4}{|l|}{ SNF Staff Characteristics } \\
\hline Staff care-team members ${ }^{a}$ & LPN, MD, SW, NP, OT, PT, ARN & SW, RN, LPN, MD, OT, PT, RD, CC & SW, LPN, NP, RN, MD, OT, PT \\
\hline Managers and Department Heads & 8 enrolled & 9 enrolled & 8 enrolled \\
\hline
\end{tabular}

${ }^{a} S W$ social worker, $L P N$ licensed practical nurse, $R N$ registered nurse, MD medical doctor, NP nurse practitioner, OT occupational therapist or assistant, $P T$ physical therapist or assistant, $R D$ registered dietician, $C C$ care coordinator, $A R N$ administrative nurse 
Table 3 Illustration of the data collection schedule in SNFs ${ }^{\mathrm{a}}$

\begin{tabular}{|c|c|c|c|c|c|c|c|c|c|c|c|c|c|c|c|c|c|c|c|c|c|c|}
\hline \multirow[t]{3}{*}{$\begin{array}{l}\text { Subject or } \\
\text { Data Source }\end{array}$} & \multicolumn{21}{|c|}{ Week } & \multirow{3}{*}{$8-9$} \\
\hline & \multirow[t]{2}{*}{$\overline{1-3}$} & \multirow[t]{2}{*}{4} & \multicolumn{19}{|c|}{$5-7$} & \\
\hline & & & $\overline{1}$ & 2 & 3 & 4 & 5 & 6 & 7 & 8 & 9 & 10 & 11 & 12 & 13 & 14 & 15 & 16 & 17 & 18 & 19 & \\
\hline \multicolumn{23}{|c|}{ Interviews and Observations } \\
\hline Patient & & r & c & $f$ & & & o & o & & o & & $f$ & & o & & o & & o & o & $f$ & & \\
\hline Caregiver & & r & c & & & $f$ & & o & & & & & & & 0 & & & & & $f$ & & \\
\hline OT & & r & $c$ & $f$ & o & & & & & o & & & & o & & & o & & o & $f$ & & \\
\hline PT & & $r$ & c & & $f$ & & o & & & & & & o & & & & o & & o & $f$ & & \\
\hline SW & $c, f$ & r & $c$ & & $f$ & o & & & & o & & & & & & & & & o & & $f$ & \\
\hline LPN & & $r$ & c & & & & & o & & & o & & & & 0 & & & 0 & & & $f$ & \\
\hline NP & $c, f$ & r & c & & o & & & & & & & 0 & & & & & o & & & & $f$ & \\
\hline MD & & r & c & o & & & & & & & & & o & & & & & & & & $f$ & \\
\hline RN & & r & c & & & $f$ & o & & & & & o & $f$ & & & o & & & & & & \\
\hline Other & $c, f$ & & c & & & o & & & & & & & & & & & & o & & & & $f$ \\
\hline \multicolumn{23}{|c|}{ Other data sources } \\
\hline Meetings & o & & o & o & o & o & o & & & o & o & o & o & o & & & o & o & o & o & o & \\
\hline Chart & & $d$ & $d$ & $d$ & $d$ & $d$ & $d$ & $d$ & & $d$ & $d$ & $d$ & $d$ & $d$ & $d$ & & $d$ & $d$ & $d$ & $d$ & $d$ & $d$ \\
\hline Document & $d$ & & $d$ & & $d$ & & $d$ & & & & & d & & $d$ & $d$ & & & $d$ & & & $d$ & $d$ \\
\hline
\end{tabular}

Key: $r$ recruitment, $c$ consent, $f$ formal interview, o observation and informal interview, $d$ chart or document review, OT occupational therapist, $P T$ physical therapist, SW social worker, $L P N$ licensed practical nurse, $N P$ nurse practitioner, $M D$ medical doctor, $R N$ registered nurse, Other = managers, department heads, administrators

allustrates the data collection schedule for a case in which the patient length of stay was 19 days. In weeks 1- 3, we assessed organizational structure. In week 4 we recruited the patient and staff. In weeks 5-7 we did field work for 19 days with the individual patient, primary caregiver and staff. In weeks 8-9, we concluded data collection activities 
individual patient. In weeks 9-10, final data collection activities were completed, including chart and document reviews and exit interviews with department heads. The lead author collected data six days per week in each SNF for the duration of the patient's SNF stay.

\section{Semi-structured interviews}

Semi-structured interviews were conducted in private to assure confidentiality and minimal disturbances. They were approximately $30 \mathrm{~min}$ in length, audio recorded, and transcribed. Transcripts were compared to audio recordings of the interviews and assessed for accuracy. In weeks 1-3 and 9-10 in each SNF, interviews were used to explore the department managers' perceptions of the organizational supports for delivering transitional care services. Interview questions were developed to examine the main concepts and relationships in the guiding models for the research. The topic list for these interviews included procedures for assessing patient needs, organizational supports for coordinating care and team work among direct care providers. Semi-structured interviews were also used to explore perceptions of staff members who delivered transitional care services. The topic list for staff interviews included strategies for engaging patients and primary caregivers, understanding of evidence-based transitional care services, use of organizational supports to deliver care, and care-team interactions. Semi-structured interviews with patients and primary caregivers were used to describe their experiences in the SNF. The topic list for patient and primary caregiver interviews included expected transitional care outcomes, participation in transitional care services, and preparedness for discharge from the SNF to home.

\section{Observations and document reviews}

The lead investigator directly observed staff members, patients and primary caregivers as transitional care services were delivered in the SNFs (see Table 3) [21]. Observations included "chance encounters" (e.g., interactions among staff or patients and staff in the hall or at the nursing stations) [19], team meetings such as care plan meetings, scheduled appointments between staff, patients and /or family caregivers, and one-to-one encounters, such as therapy sessions and nursing rounds. The lead author's recorded observations in field notes which were transcribed daily in formal field notes $[23,26]$.

Document reviews of procedure manuals, medical charts and/or discharge documents were completed daily. Tools for reviewing documents were developed to assess the main concepts in the guiding models for the research. The purpose of document reviews was to record (a) written communication about transition needs, goals, implementation of goals, and instructions to guide care at home and (b) policies and procedures for providing transitional care services.

\section{Data analysis}

Data were organized for analysis in Atlas.ti (Scientific Software Development, Berlin, Germany) [27]. We used thematic analysis, a method of qualitative analysis in which data are labeled with codes and categorized to identify broader ideas or "themes" within the entire data set $[22,28]$. Interview transcripts, field notes and case documents were reviewed and then coded using the concepts and definitions identified in Table 1 (e.g., organizational supports, care-team interactions, transitional care services) $[22,28]$. A second analyst coded a random sample of $10 \%$ of the data to evaluate the reliability of the coding; agreement between data coders was $96 \%$ [28]. To address Aim 1, data coded as organizational structures and transitional care services were cross-tabulated in data matrices; similarities and differences in organizational supports and transitional care services were described within and across SNFs [22]. For example, data coded as staff knowledge (an organizational structure) were cross-tabulated with data coded with each of the eight transitional care activities; then summaries of the data describing staff knowledge and each transitional care activity were written within and across SNFs. Similarly, for Aim 2, data coded as care-team interactions and transitional care services were cross-tabulated in matrices; then similarities and differences in care-team interactions and transitional care services were described within and across SNFs [22]. To address Aim 3, data coded as transitional care services were summarized and used to write narratives describing transitional care services that existing staff provided within and across SNFs. After data were analyzed, study findings were presented to SNF staff members in SNF 1 and 2; even with repeated attempts to schedule, staff members in SNF 3 were not available. In SNF 1 and 2, staff concurred with main findings and used the findings to discuss opportunities to engage in performance improvement. Finally, narratives were written to describe the main findings for each study aim. All investigators participated in thematic analysis.

\section{Results}

The sample of participants in three SNFs included three patients, two primary caregivers and 49 staff members (see Table 2). The data from the case studies included 66 interview transcripts, 235 field notes, and 35 case documents. A total of 527 sections of text from the interviews, field notes and case documents were coded as organizational structures, care-team interactions or transitional care services. Analysis of the coded data revealed 
three main themes: (a) organizational support and staff members who delivered transitional care services, (b) care-team interactions and delivery of transitional care services, and (c) the challenge in providing evidencebased transitional care services. Main findings are described sequentially by theme below.

\section{Theme 1: Organizational support and staff members who delivered transitional care services}

We found that staff more effectively delivered transitional care services when organizational structure was available to inform or coordinate their work as a team. A physician in SNF 1 noted the benefits of strong organizational support.

"I have worked in facilities where the patient is ready to go and nobody knows it. But with all our meetings and hand-offs here, you know everything that you need for all the prescriptions, all the equipment, what I need to teach the patient. So it is usually very, very planned." (Physician)

Below, we provide specific descriptions of staff knowledge, care routines and tools that appeared to have the greatest impact on the ability of staff to deliver transitional care services.

\section{Staff Knowledge}

In SNF 1, a physician, social workers, rehabilitation therapists, and selected nurses understood the need for transitional care and were skilled in preparing the patient to transfer home. For example, the social worker recognized the need to help families understand routines in the SNF and the expected discharge date.

"My job is to...negotiate between the rehabilitation time under Medicare, what the patient is looking for, what the family is looking for, and to figure-out how to get everybody on the same page."

In SNF 1, we also observed that staff members skillfully taught the patient to how to self-manage her care at home. For example, near the day of discharge, the patient clearly articulated changes in her medications and what to expect at home.

"They have been watching my Dilantin levels here and I am told they have adjusted that medicine and that my levels will return to normal. My doctor knows about that too." (Patient)

"I have been using OxyContin for pain but that is changing too. I am starting Tylenol now and I will take that when I get home as well." (Patient)
In SNFs 2 and 3, however, staff members had little understanding of evidence-based transitional care services. For example, a nurse misinterpreted the definition and purpose of transitional care.

"It's a way to care for those people that are going to stay with us...we would transition them from one of our units to another." (Nurse)

In these facilities, gaps in staff knowledge were associated with omissions in transitional care services. Most commonly, staff did not effectively engage and train family caregivers. In SNF 2 and 3, on the day of discharge, caregivers described unmet needs for information about caring for their family members at home.

"I wish I knew more about what to look for if [patient] started getting signs of getting sick or her health started failing again; what to do and who to call on for that." (Family Caregiver)

"I know they worked with my mother but they should bring a family member in too and teach them what we should be able to do...to help this person to maneuver around like they did in the facility." (Family Caregiver)

\section{Care Routines and Tools}

In SNF 1, staff members used a schedule of routine meetings to plan and implement transitional care services. These included intra-departmental meetings (e.g., rehabilitation, social work and nursing) to identify the patient's needs for care at home, inter-departmental meetings to develop comprehensive assessments, and "family meetings" with patients, primary caregivers and SNF staff.

"We learned that it really does help to have the family meeting early in the admission because, if we don't, there is not enough time to get the assessment, plan, or know what is going to be needed at home."

(Director of Nursing)

In SNF 1, we also found that staff used specific tools in the medical record to document and schedule events in care. For example, in our review of the patient's medical record, we saw that social workers and rehabilitation therapists used standardized templates to document patient needs, the plan for care at home, and the patient's ability to walk and provide self-care.

In SNFs 2 and 3, however, staff members worked without care routines and tools which limited their ability to coordinate delivery transitional care services. In SNF 3, a 
care plan meeting was never convened. In SNF 2, a care plan meeting with patient, primary caregiver and SNF staff was convened, but two days before the patient returned home. In this SNF, the director of nursing described the need to plan transitions in care earlier.

"We need more timely planning...we can say on Monday that this patient is discharging next Monday...then Thursday comes and the rush kicks in. It doesn't work." (Director of Nursing)

In SNFs that lacked care routines for delivering transitional care services, last minute plans and instructions were confusing to patients and primary caregivers. In SNF 3, at the time of discharge to home, the patient was angry about confusion in her medication orders.

"I don't know what they are saying here. I will go see my own doctor when I get home. She will tell me what I need to take." (Patient)

Finally, across the SNFs, we found gaps in care routines and tools; for example, we did not observe staff that coordinated transitional care using templates to guide medication reconciliation, standardized care routines for transferring information to primary care, or electronic medical record systems to integrate work among staff in different disciplines.

\section{Theme two: care-team interactions and delivery of transitional care services}

Across the SNFs, we found that the informal interactions among individual patients, primary caregivers and staff allowed individualized care to be planned and implemented. Below, we describe interactions which appeared to have the greatest impact on the ability of staff to deliver transitional care services.

\section{Interactions associated with Connections and} Information Exchange on Care-teams

In SNF 1 and inconsistently in SNF 2, staff members were approachable to others and pitched in to help each other implement transitional care services. In SNF 1, staff members described the importance of being approachable and sharing information.

"I like to be available...I want [staff] to know they can come to me and ask for help..." (Nurse)

"We have our rehabilitation meeting on Tuesday and everybody gets together and assesses what the patient needs when they are discharged...I would say that is our greatest strength here, having that open communication between all the disciplines." (Quality Assurance Nurse)

In SNF 1, we found that the easy flow of information contributed to effective transitional care services, for example, a nuanced and patient-centered assessment of the patient's preparedness for returning home. A social worker described her understanding of the patient's preferences, and how the team was working to honor them.

"Some folks need to feel like they are driving the bus - for [patient name], we need to let her do that. The physical therapist...realized that the cervical collar was really the big issue - because she can't see her feet when she wears it. We are very concerned to reduce her risk of falls, so we need to follow the therapist's advice; we will work with her here until the collar is off." (Social Worker)

In SNFs 2 and 3, however, where care-team interactions were observed less often, staff delivered transitional care in isolation of other team members and habitually worked alone, or in pairs with patients.

"It's just easier for me to do this [discharge planning] myself than to try to coordinate this work with someone else." (Nurse Care Coordinator)

Two days later, the same nurse described a backlog of transitional care services and was overwhelmed by her workload.

"I'm running around like a chicken with its head cutoff. The [Agency Name] did not order Oxygen - now on top of everything else, I have to figure that out." (Nurse Care Coordinator)

In SNF 2, a physical therapist lamented barriers to communication that limited her ability to follow-up on patient and caregiver needs.

"We write notes, but I do not think they are closely followed [by other staff]. So what I have to do is try to find the family...it is hard because they are not here when I am here...I can tell the rehabilitation director [what to tell them], but that is not a guarantee that it will make it to the family." (Physical Therapist)

In these SNFs, staff members were sometimes afraid to provide feedback and circumvented conversations with key members of the care-team. For example, one department head related how staff avoided the physician and expected her to communicate with him for the group. 
"If [staff members] have any issues and think [physician name] can help, they come to $m e$, and say 'can you, you know, talk to him about it." (Director of Nursing)

In SNF 2 and 3, limitations in care-team interactions were associated with less effective information flow among team members, which limited the quality of transitional care services. In SNF 2 for example, a care coordinator planned a discharge date with the patient; yet, two days before the discharge, the occupational therapist and physician were not aware the discharge was pending.

\section{Interactions associated with Problem Solving on Care-teams}

In SNF 1, care-team members proactively approached problems and conflicts in overlapping subgroups, including the patient, occupational therapist and nurse; the physician, social worker and nurse; and others. A nurse explained how team interactions helped her to prepare the patient for returning home.

"Just having [team members] there gives us a chance to solve individual problems and to hear what the patient's or family member's questions are. This gives a chance to talk about the plan and prevent some of the last minute questions..." (Nurse)

Problem-solving interactions on the care-team appeared to support the coordination of transitional care services. For example, the social worker assessed the need to help the patient change agencies for home health aides; she solved problems with the patient and community social worker; and she relayed feedback to and from other care-team members in the SNF. The patient appreciated well-coordinated transitional care.

"They helped set things up at home...even with the holidays, they found out what was needed, like learning my community worker's name and working with him...I was worried. I would not have been able to handle it all." (Patient)

However, limited connections and information exchange on care-teams in SNFs 2 and 3 appeared to constrain the degree that team members worked together to solve problems; rather, one or two clinical experts appeared to solve problems for the entire team. In SNF 2, for example, the director of nursing - who supervised all clinical staff in the SNF - directly intervened to address an impasse in discharge planning. The director of nursing convened a family meeting and led a conversation about negotiating care with the patient at home.
"You have to teach [patient name] to compromise... We are asking her to make some big changes...You know, work with her so she can learn." (Director of Nursing)

Though ultimately effective, the director of nursing's intervention was an act of crisis management, two days before discharge, when she learned that staff had neither met with the caregivers nor discussed the conflicts in the family that limited transition planning.

Across the study SNFs, we observed significant gaps in problem solving. Most importantly, conversations frequently did not include interactions with family caregivers, even though they were present in the facilities and expressed a desire for greater participation.

\section{Theme 3: The challenge in providing evidence-based transitional care services}

We found wide variation in transitional care services, but only one of three SNFs was able to deliver most of the recommended services using existing staff. Of the potential transitional care services described in the literature, we found that staff in all 3 SNFs: (a) reconciled medications lists from the hospital and the SNF, (b) taught patients strategies for safe physical function, (c) provided verbal instructions for medication administration, (d) referred patients for home care, and (e) recommended follow-up with primary care providers. Across the study SNFs, staff inconsistently: (a) assessed patient goals and needs at home, (b) reconciled medication lists from the SNF and home, (c) assessed primary caregiver needs or engaged primary caregivers in treatment plans, (d) taught written transition plans and (e) provided detailed written instructions for care at home. Finally, no SNF staff members transferred treatment information to follow-up medical providers or visited/called patients or caregivers at home to reinforce transition plans.

In SNF 1, compared to SNFs 2 and 3, we found that staff delivered substantially more transitional care services, and more effectively prepared the patient for continuing care at home (see Table 4). In the narrative that follows we describe how staff in SNF 1 delivered transitional care services, to highlight practices that might inform future interventions to improve transitional care in SNFs.

First, early in the SNF stay, staff assessed the patient's transition needs (such as changes in medications and environmental safety at home) and learned the patient's preferences, for example, the patient's hope to remain in the SNF until her neck brace was discontinued. Second, staff consistently taught the patient strategies for safely walking, washing, and cooking at home; for example, an occupational therapist used role-play kitchen activities to teach the patient, who subsequently noted how to use her walker at home. 
Table 4 Findings: transitional care services provided by week of patient admission

\begin{tabular}{|c|c|c|c|c|}
\hline$\overline{S N F}$ & Week 1 & Week 2 & Week 3 & Week 4 \\
\hline 1 & $\begin{array}{l}\text { - Thoroughly assessed needs for care } \\
\text { at home } \\
\text { - Reconciled medication lists } \\
\text { - Taught medications and treatment } \\
\text { goal }\end{array}$ & $\begin{array}{l}\text { - Team meeting to engage patient and } \\
\text { plan care at home } \\
\text { - Contacted community physicians to } \\
\text { plan medical goals }\end{array}$ & $\begin{array}{l}\text { - Team taught self-management skills; } \\
\text { - Social worker referred and activated } \\
\text { community supports } \\
\text { - MD taught goals and medications }\end{array}$ & $\begin{array}{l}\text { - Provided written instructions } \\
\text { - Scheduled MD follow-up } \\
\text { - Did not transfer records to } \\
\text { follow-up MD or contact } \\
\text { patient at home }\end{array}$ \\
\hline 2 & $\begin{array}{l}\text { - Assessed functional needs } \\
\text { - Did not assess patient/caregiver gaps } \\
\text { in knowledge about dialysis or medications } \\
\text { - Reconciled only hospital and SNF } \\
\text { medication lists }\end{array}$ & $\begin{array}{l}\text { - Rehabilitation therapists taught the } \\
\text { patient (but not caregivers) } \\
\text { - Did not engage family members in planning } \\
\text { for the patient's complex needs at home }\end{array}$ & $\begin{array}{l}\text { - Assessed gaps in discharge and self-care } \\
\text { ability for the patient at home } \\
\text { - Team meeting to plan care at home } \\
\text { - MD reconciled medications and taught } \\
\text { the patient }\end{array}$ & $\begin{array}{l}\text { - Referred support for new } \\
\text { dialysis } \\
\text { - Partial written instructions } \\
\text { provided } \\
\text { - Did not schedule MD } \\
\text { follow-up, transfer records } \\
\text { to follow-up MD or contact } \\
\text { patient at home }\end{array}$ \\
\hline 3 & $\begin{array}{l}\text { - Assessed risk for falls and need for } \\
\text { lower extremity rehabilitation. } \\
\text { - Did not reconcile medication lists, identify } \\
\text { caregiver needs, or address recent cardiac } \\
\text { changes }\end{array}$ & $\begin{array}{l}\text { - Planned care in SNF but did not plan } \\
\text { the transition to home } \\
\text { - Did not engage family members } \\
\text { - The patient disengaged from SNF staff } \\
\text { and planned goals with primary care }\end{array}$ & $\begin{array}{l}\text { - The patient scheduled MD follow-up } \\
\text { - Did not create integrated plan for care } \\
\text { at home } \\
\text { - Did not contact the community social } \\
\text { worker } \\
\text { - Taught self-management for mobility } \\
\text { and transfer safety }\end{array}$ & $\begin{array}{l}\text { - Referred home care } \\
\text { - Taught a written list of } \\
\text { discharge medications } \\
\text { - Did not schedule MD } \\
\text { follow-up, transfer records to } \\
\text { primary care or contact } \\
\text { the patient at home }\end{array}$ \\
\hline
\end{tabular}


"I understand now. I can hold on [to] this thing even when I reach something up here." (Patient)

Third, staff consistently re-assessed the patient's response to treatment, which fostered their ability to plan the transition home. For example, midway through the patient's stay, a social worker recognized the patient's increasing confidence.

"I feel like she [the patient] is coming into her own...

She had the care plan meeting...then, physical therapy pulled her in [and taught her safety skills]...and she understands now what her goal is...I think she feels a whole lot better [about going home]." (Social Worker)

Fourth, staff wrote detailed instructions and used them to reinforce teaching about care at home, including medication administration, scheduled appointment names and dates, contacts for community support and home care services, and a list of warning signs that indicated the need to follow-up with a medical provider. On the day of discharge, the patient was very satisfied with transitional care in the SNF.

"This is a very, very, very overall equipped

convalescent facility... everyone here pays attention to what you need, every detail." (Patient)

\section{Discussion}

In a sample of three purposefully selected SNFs, we found that existing staff members in one SNF effectively delivered evidence-based transitional care services, while those in two facilities provided more fragmentary transitional care that inconsistently addressed the goals of patients and their primary caregivers. An earlier study indicated that $22 \%$ of older adults either visited an emergency department without hospitalization or were re-hospitalized within 30 days of discharge from a SNF [6]. The current study suggests an explanation for these findings by describing gaps and inconsistencies in transitional care services that may contribute to poor outcomes for older adults in SNFs after they return home. Findings in the study do not account for differences in income, community support, primary care, and other factors that might contribute to poor outcomes. However, our findings of gaps in transitional care services suggest that poor outcomes may be related to modifiable strategies for delivering care in SNFs. This finding also suggests the need to test the feasibility and effectiveness of evidence-based transitional care for SNF patients.

Our finding, that one SNF with robust organizational structure and care-team interactions more effectively delivered transitional care services than two SNFs with limited organizational structure and care-team interactions, suggests two strategies for improving the way existing staff deliver transitional care. The first strategy is to develop organizational structure in SNFs that supports staff members who deliver transitional care; for example, new procedures in SNFs for creating written self-care plans for patients to use at home. The second strategy is to develop interactions on patient care-teams that promote connections, information exchange and problem solving; for example, carefully listening to family caregivers to evaluate their understanding of new instructions for care at home. In two prior studies, transitional care services were associated with reductions in 30 day hospital readmissions of SNF patients [10, 18]. Our findings potentially extend these studies and suggest that strengthened supports and training for staff who deliver transitional care are needed to reduce hospital readmissions after SNF patients return home.

These findings suggest practical implications for policymakers and research. In 2014, the U.S. Congress passed a value based purchasing program for SNFs, which will create penalties for SNFs (based on Medicare reimbursement rates for care in SNFs) to prevent avoidable re-hospitalizations of SNF patients 30 days after discharge [3]. A first step to improving transitional care, and potentially patient outcomes, might be to develop staff knowledge about care transitions, including training to help staff: (a) recognize that SNF patients are at risk for poor outcomes during transitions to home and (b) learn the importance of key transitional care steps for minimizing these risks $[29,30]$. The frequently observed focus on "discharge planning" in the last 2-3 days of SNF stays suggests that staff do not appreciate the scope and importance of transitional care. With greater awareness, existing staff in SNFs may be receptive to the changes in workflow and additional steps needed to implement evidence-based transitional care interventions and prevent avoidable re-hospitalizations after patients return home [31, 32]. Training materials in the ReEngineered Discharge (RED) Toolkit are a useful starting point to develop new educational materials $[9,10,32]$; in particular, Tools $3-6$ which describe transitional care services associated with reduced rates of hospital readmissions, such medication reconciliation, education strategies for assuring that patients understand new healthcare instructions, written transition plans for use at home, and calls or visits to patient homes after discharge [13, 32].

The findings also suggest the need for new tools and procedures to plan patient transitions from the SNFs to home $[9,18]$. We found that staff in two SNFs delivered many transitional care services in the last 24 to $72 \mathrm{~h}$ of patient stays; this suggests the need to start transitional care services earlier and establish schedules to move staff stepwise through a process to prepare SNF patients 
and caregivers for discharge. Moreover, data are not currently available which describe ways that electronic medical records might be adapted in SNFs to support timely and collaborative work of physicians, social workers, nurses and rehabilitation therapists. As financial pressures continue to reduce the average length of stay in SNFs, organizational supports, such as new tools in electronic medical records systems, will be important resources for improving the timeliness and number of team member contributions to transitional care services. New transitional care tools in electronic medical records systems may also be useful to managers and department heads in SNFs who oversee performance improvement and quality assurance in SNFs. The transitional care practice guidelines developed by the American Medical Directors Association includes tools that SNF managers might use to monitor the quality of transitional care services; for example, the frequency of caregiver inclusion in care plan meetings, hand-offs of clinical information to follow-up physicians, and post-discharge follow-up calls or visits [29].

Finally, our findings have implications for practice and research about patient- and family- centered care-teams in SNFs. Consistent with earlier studies [19, 20, 21, 33], our findings suggest the need to cultivate formal and informal care-team interactions among physicians, nurses, rehabilitation therapists and social workers who directly prepare patients for transitions in care. Findings in this study extend earlier research by identifying strategies to engage family caregivers and establish their important roles on patient care-teams. For example, the findings suggest the need to ask questions about caregiver roles and responsibilities at home; to explain new information carefully, especially critical details in planning such as the expected day of discharge; and to make time for solving problems in groups with patients and their primary caregivers. Training tools in the CONNECT for Better Falls Prevention in Nursing Homes study may help staff members recognize how their interactions with patients and primary caregivers influence the effectiveness of problem solving on patient care-teams [34]; in particular, role playing exercises in the CONNECT training tools are potentially helpful models, as they create opportunities for staff to practice giving and receiving feedback with each other and in simulated encounters with patients or primary caregivers.

These findings come with several caveats. First, the limited number of SNFs studied may limit the transferability of the findings [35, 36]. For example, differences in ownership in study SNFs may have contributed to the variations in transitional care services, organizational support and care-team interactions; quantitative studies with larger samples of SNFs are warranted to examine the relationship between facility-level factors (e.g., ownership, profit status, staffing, and patient populations) and transitional care provided in SNFs. Second, our study was designed to closely examine how differences in organizational support and care-team interactions were related to the quality of transitional care in three SNFs; it was not designed to study how differences in the needs of patients and primary caregivers - within the same SNF - may have influenced the quality of transitional care. Additional research may be needed to evaluate the relationship between SNF patient factors, such as health literacy and perceived social support, and the outcomes of transitional care services. Third, SNF staff members were aware that the study focused on transitional care, which may have influenced their behavior and introduced bias into the data. However, this limitation was attenuated by the design for data collection and analysis, which included triangulation of data in the analysis that were collected from multiple sources (e.g., observations and interviews), providers and points of time. Fourth, data were collected by the lead investigator who may have had preconceptions that biased the data collection and analysis; this limitation was managed by procedures for insuring rigor [21], in which a second coder verified $10 \%$ of the data. Finally, the study did not examine patient outcomes at home. Despite these caveats, the study permitted prolonged and in-depth data collection in three diverse SNFs; it also facilitated a description of practical strategies to train and support existing staff in SNFs that deliver transitional care.

\section{Conclusions}

Existing staff members can effectively deliver evidencebased transitional care services with appropriate organizational structure and care team interactions; research is needed to determine the influence of transitional care interventions on patient outcomes after SNF discharge.

\section{Ethics}

The protocols in this study were approved by the Institutional Review Board at Duke University and underwent annual review (Pro00014871).

\section{Consent to participate}

A written, informed consent procedure was used with all study participants, including use of a plain language statement of study procedures and risks. Individuals who provided study data signed an informed consent.

\section{Consent to publish}

Not applicable. 


\section{Availability of data and materials}

Data supporting study findings are contained in the manuscript. Some data will not be made available as publication of the documents, field notes and interview transcripts from the case studies would compromise the confidentiality of study participants.

\section{Abbreviation \\ SNF: skilled nursing facility.}

\section{Competing interests}

The authors declare that they have no competing interests.

\section{Authors' contributions}

MT, CCE, MN, JB and RA designed the study. MT recruited study sites and the participants. MT collected the data, supervised the transcription, wrote field notes and did the primary coding of field notes and transcriptions. During data collection and coding of the data, RA and CCE consulted with MT and provided guidance to assure rigor and consistency in study procedures. JB confirmed the reliability of the coding by redundantly coding $10 \%$ of the data. MT, CCE, MN, JB and RA conducted the thematic analysis to identify themes in the coded data. MT, CCE, MN, JB and RA wrote the manuscript and developed the figure and tables. All authors read and approved the final manuscript.

\section{Acknowledgements}

Although we are not able to mention them by name, the authors wish to acknowledge and express our gratefulness to the organizations and individuals who participated in the research.

\section{Funding}

Mark Toles was supported by the John A. Hartford Foundation, Claire M. Fagin Postdoctoral Fellowship and by the National Center for Advancing Translational Sciences, National Institutes of Health, grant numbers: 1KL2TR001109 and 1UL1TR001111.

\section{Author details}

'University of North Carolina at Chapel Hill, School of Nursing, 7460 Carrington Hall, Chapel Hill, NC 27599, USA. ${ }^{2}$ School of Medicine and the Geriatric Research, Education and Clinical Center (GRECC), Durham Veterans Affairs Medical Center, Duke University, DUMC 3469, Durham, NC 27710, USA. ${ }^{3}$ NewCourtland Center for Transitions and Health, University of Pennsylvania School of Nursing, Room 341 Fagin Hall, 418 Curie Blvd., Philadelphia, PA 19104-4217, USA. ${ }^{4}$ Medical University of South CarolinaCollege of Nursing, Room 50899 Jonathan Lucas St., Charleston, SC 29425-1600, USA. ${ }^{5}$ University of North Carolina at Chapel Hill, School of Nursing, 7460 Carrington Hall, Chapel Hill, NC 27599, USA.

Received: 16 January 2015 Accepted: 5 May 2016 Published online: 17 May 2016

\section{References}

1. $\mathrm{Ng} \mathrm{T}$, Harrington $\mathrm{C}$, Kitchener M. Medicare and medicaid in long-term care. Health Aff (Millwood). 2010;29(1):22-8. doi:10.1377/hlthaff.2009.0494.

2. Sofaer S. Navigating poorly charted territory: Patient dilemmas in health care "nonsystems". Med Care Res Rev. 2009;66(1 Suppl):75S-93S. doi:10. $1177 / 1077558708327945$

3. Medicare Payment Advisory Commission. Report to Congress. Medicare Payment Policy. 2013. http://www.medpac.gov/-documents-/reports. Accessed 7 Apr 2015.

4. Coleman EA. Falling through the cracks: Challenges and opportunities for improving transitional care for persons with continuous complex care needs. J Am Geriatr Soc. 2003;51(4):549-55.

5. Medicare Payment Advisory Commission. Report to the Congress. Medicare payment policy. 2013. http://medpac.gov/documents/reports/mar13_ entirereport.pdf. Accessed 5 Sept 20142013.

6. Toles M, Anderson RA, Massing M, Naylor MD, Jackson E, Peacock-Hinton S et al. Restarting the cycle: incidence and predictors of first acute care use after nursing home discharge. J Am Geriatr Soc. 2014. doi:10.1111/jgs.12602.
7. Hall RK, Toles M, Massing M, Jackson E, Peacock-Hinton S, O'Hare AM et al. Utilization of acute care among patients with ESRD discharged home from skilled nursing facilities. Clin J Am Soc Nephrol. 2015. doi:10.2215/cjn.03510414.

8. Coleman EA, Boult C. Improving the quality of transitional care for persons with complex care needs. J Am Geriatr Soc. 2003;51(4):556-7.

9. Toles M, Young M, Ouslander JG. Improving care transitions in nursing homes. Generations. 2012;36(4):78-85.

10. Berkowitz RE, Fang Z, Helfand BK, Jones RN, Schreiber R, Paasche-Orlow MK Project ReEngineered Discharge (RED) lowers hospital readmissions of patients discharged from a skilled nursing facility. J Am Med Dir Assoc. 2013;14(10):736-40. doi:10.1016/j.jamda.2013.03.004.

11. Hansen LO, Young RS, Hinami K, Leung A, Williams MV. Interventions to reduce 30-day rehospitalization: a systematic review. Ann Intern Med. 2011; 155(8):520-8. doi:10.1059/0003-4819-155-8-201110180-00008.

12. Naylor MD, Aiken LH, Kurtzman ET, Olds DM, Hirschman KB. The care span: The importance of transitional care in achieving health reform. Health Aff (Millwood). 2011;30(4):746-54. doi:10.1377/hlthaff.2011.0041.

13. Verhaegh KJ, MacNeil-Vroomen JL, Eslami S, Geerlings SE, de Rooij SE, Buurman BM. Transitional care interventions prevent hospital readmissions for adults with chronic illnesses. Health Aff (Millwood). 2014;33(9):1531-9. doi:10.1377/hlthaff.2014.0160.

14. Lee J. An imperative to improve discharge planning: Predictors of physical function among residents of a medicare skilled nursing facility. Nurs Adm Q. 2006;30(1):38-47.

15. Popejoy LL, Dorman Marek K, Scott-Cawiezell J. Patterns and problems associated with transitions after hip fracture in older adults. J Gerontol Nurs. 2013;39(9):43-52. doi:10.3928/00989134-20130620-01.

16. Donabedian A. Evaluating the quality of medical care. Milbank Q. 2005;83: 691-729.

17. Anderson RA, Toles MP, Corazzini K, McDaniel RR, Colon-Emeric C. Loca interaction strategies and capacity for better care in nursing homes: a multiple case study. BMC Health Serv Res. 2014;14:244. doi:10.1186/14726963-14-244.

18. Donabedian A. The definition of quality and approaches to its assessment Ann Arbor: Health Administration Press; 1980.

19. National Transitions of Care Coalition. Transitions of Care Measures. 2008. http://www.ntocc.org/portals/0/TransitionsOfCare_Measures.pdf. Accessed 16 July 2009.

20. Colon-Emeric C, Pinheiro SO, Anderson RA, Porter K, McConnell E, Corazzini $\mathrm{K}$, et al. Connecting the learners: improving uptake of a nursing home educational program by focusing on staff interactions. Gerontologist. 2013. doi:10.1093/geront/gnt043.

21. Toles M, Barroso J, Colon-Emeric C, Corazzini K, McConnell E, Anderson RA. Staff interaction strategies that optimize delivery of transitional care in a skilled nursing facility: a multiple case study. Fam Community Health. 2012; 35(4):334-44. doi:10.1097/FCH.0b013e31826666eb.

22. Yin RK. Case study research: Design and methods. 2nd ed. Beverly Hills: Sage Publishing; 1994

23. Anderson RA, Crabtree BF, Steele DJ, McDaniel Jr RR. Case study research: The view from complexity science. Qual Health Res. 2005;15(5):669-85. doi:10.1177/1049732305275208.

24. Patton M. Qualitative Research and Evaluation Methods. 3rd ed. Thousand Oaks: Sage Publications, Inc: 2002.

25. Centers for Medicare and Medicaid Services. Nursing Home Compare. 2012. http://www.medicare.gov/NursingHomeCompare/search.aspx.

26. Barley SR, Kunda G. Bringing work back in. Org Sci. 2001;12:76-95.

27. Miles MB, Huberman AM. Qualitative data analysis. Thousand Oaks: Sage Publications; 1994

28. Silverman D, Marvasti A. Doing qualitative research. London: Sage Publications: 2008

29. American Medical Directors Association. Transitions in Care in the Long Term Continuum Clinical Practice Guideline. Columbia: AMDA; 2010.

30. Ouslander JG, Berenson RA. Reducing unnecessary hospitalizations of nursing home residents. N Engl J Med. 2011;365(13):1165-7. doi:10.1056/ NEJMp1 105449

31. Berkowitz RE, Jones RN, Rieder R, Bryan M, Schreiber R, Verney S, et al. Improving disposition outcomes for patients in a geriatric skilled nursing facility. J Am Geriatr Soc. 2011;59(6):1130-6. doi:10.1111/j.1532-5415.2011. 03417.x.

32. Jack BW. Project RED, (Re-Engineered Discharge). 2013. http://www.bu.edu/ fammed/projectred/. Accessed 1 Nov 2013. 
33. Colon-Emeric C, McConnell E, Pinheiro S, Corazinni K, Porter K, Simpson KM. CONNECT for better fall prevention in nursing homes: results from a pilot intervention ctudy. J Am Geriatr Soc. 2013;61(12):2150-9. doi:10.1111/jgs.12550.

34. Anderson RA, Corazzini K, Porter K, Daily K, McDaniel Jr RR, Colon-Emeric C. CONNECT for quality: protocol of a cluster randomized controlled trial to improve fall prevention in nursing homes. Implementation Sci. 2012;7:11. doi:10.1186/1748-5908-7-11.

35. Eisenhardt KM. Building theories from case study research. Acad Manage Rev. 1989;14:532-50.

36. Gerring J. What is case study and what is it good for? Am Pol Sci Rev. 2004; 98:341-54.

Submit your next manuscript to BioMed Central and we will help you at every step:

- We accept pre-submission inquiries

- Our selector tool helps you to find the most relevant journal

- We provide round the clock customer support

- Convenient online submission

- Thorough peer review

- Inclusion in PubMed and all major indexing services

- Maximum visibility for your research

Submit your manuscript at www.biomedcentral.com/submit 